\title{
Systemic Risk and Macroeconomic Fat Tails
}

\author{
Spiros Bougheas ${ }^{1(\bowtie)}$, David Harvey ${ }^{1}$, and Alan Kirman ${ }^{2}$ \\ 1 School of Economics, University of Nottingham, Nottingham NG7 2RD, UK \\ spiros.bougheas@nottingham.ac.uk \\ 2 École des Hautes Études en Sciences Sociales, CAMS - EHESS, Paris, France
}

\begin{abstract}
We propose a mechanism for shock amplification that potentially can account for fat tails in the distribution of the growth rate of national output. We argue that extreme macroeconomic events, such as the Great Depression and the Great Recession, were preceded by significant turmoil in the banking system. We have developed a model of bank network formation and presented numerical simulations that show that, for the benchmark case, aggregate credit follows a random walk. When we introduce fire sales the model does not only produce larger variations in the growth of aggregate credit but also shows that there is an asymmetry between booms and busts that is also consistent with empirical evidence.
\end{abstract}

Keywords: Systemic risk $\cdot$ Banking system $\cdot$ Aggregate risk $\cdot$ Financial network $\cdot$ Fat tails

\section{Introduction}

The two most severe macroeconomic crises of the last 100 years, namely, the Great Depression of the 1930s and the Great Recession that commenced at the close of the first decade of the current century, were preceded by extreme events in financial markets in general and the banking system in particular. In a recent study, Schularick and Taylor (2012) have empirically identified a historical link between the level aggregate credit in the economy and macroeconomic performance. They argue that aggregate credit can be a powerful predictor of economic crises, especially, rare catastrophic events.

Our aim is to provide a microfoundational explanation for the above relationship. In this work we focus on the behavior of aggregate credit. In particular, we analyze the dynamics of aggregate bank credit in an economy where all financial transactions are intermediated through the banking system. Viewing the financial system as a network of banks that are connected through their financial obligations to each other, we examine how the impact of shocks on the asset side of the banking balance sheets may disrupt the supply of aggregate credit.

Each period the capacity of a bank to finance new projects depends on the size of its balance sheet which, in turn, depends on the success rate of the projects that it financed the period before. Each period, the total capacity of the banking system to finance new projects entirely depends on the aggregate

(C) The Author(s) 2018

P. Commendatore et al. (eds.), The Economy as a Complex Spatial System,

Springer Proceedings in Complexity, DOI 10.1007/978-3-319-65627-4_6 
liquidity available within the system. At the beginning of each period each bank's available liquidity (reserves) is equal to the sum of its household deposits plus its equity.

Projects are allocated sequentially and randomly across banks. A bank that faces a demand for funds but has run out of liquidity can borrow from other banks. This process creates a network of banks where its links, that reflect interbank exposures, are both directed and weighted.

As banks are unable to completely diversify their loan portfolios they can become insolvent. This will be the case when the total loan repayments (from both entrepreneurs and other banks) are insufficient to cover their obligations to their depositors and other banks. In order to clear the banking system when some banks become insolvent we apply the method suggested by Eisenberg and Noe (2001). Insolvencies can propagate through the banking network. When one bank is unable to meet its obligations to another bank, the latter bank might itself become insolvent even if it would have remained solvent had its loans to the originally failed bank been repaid. The bankruptcy resolution process terminated when there are no insolvent banks left. The number of bank failures will depend on (a) the distribution of initial losses across the banking system, and (b) the structure of the financial network (see, for example, Acemoglu et al. 2015).

As long as the liquidation of assets held by insolvent institutions does not depress the market values of these assets the total systemic losses by the end of the resolution process will be equal to the initial losses due to the inability of entrepreneurs to repay their loans. However, as Shleifer and Vishny (1992) have argued during systemic episodes, exactly because there are many failing institutions, the market value (liquidation value) of the assets can drop below their corresponding book values (fire sales). These drops in asset prices forces other institutions to reevaluate their own assets thus potentially causing new rounds of failures. ${ }^{1}$

In our model, when we do not allow for fire sales, the value of aggregate credit provided by the banking network follows a random walk. This is because the capacity of the banking network to provide credit each period depends on the availability of reserves which in turn depends on the performance of aggregate loans the period before. Given that shocks are normally distributed each period it follows that aggregate lending activity follows a random walk. When we introduce fire sales we observe that systemic losses can be much greater than initial losses thus introducing fat tails on the lower end of the distribution of aggregate credit. Under the supposition that aggregate credit is positively correlated with aggregate output our approach might be useful for accounting two features of business cycles: (a) the asymmetry in booms and busts (Acemoglu and Scott, 1991), and (b) macroeconomic fat tails Acemoglu et al. 2017a).

Our work is related to many strands of the economics literature. Our main premise is that bank leverage can be the source of systemic risk which in turn can lead to fat tails in the distributions of many macroeconomic aggregates.

${ }^{1}$ For models of fire sales see Diamond and Rajan (2011) and Caballero and Simpsek (2013). For a review of the literature on fire sales, see Shleifer and Vishny (2011). 
The relationship between leverage in financial markets and fat tails is also addressed by Thurner et al. (2012).

In recent years a number there have been some attempts to build network models of the economy that can account for the fat tails in the distribution of the growth rate of national output. This literature has been motivated by the inability of traditional DSGE models to account for such fat tails (see Ascari et al. 2015). Acemoglu et al. (2012, 2017a) have analyzed production networks where the aggregate effects of idiosyncratic shocks depend on both the initial distribution of shocks and the structure of the network. ${ }^{2}$ Anthonissen (2016) considers dynamic versions of similar economies. Thurner et al. (2012) show how leverage, through bankruptcies, can exacerbate volatility.

There is also a growing related literature that develops agent-based models to study the relationship between financial markets and the macroeconomy. Ashraf et al. (2017) integrate a banking sector with an agent-based economy where the source of turmoil is the market for goods. In contrast, in our work we view the financial sector as the one being responsible for the amplification effects on shocks. Battiston et al. (2007) consider the propagation of bankruptcies in production networks while the source of system risk in Geanakoplos et al. (2012) is the housing market. For an empirical investigation of the relationship between the macroeconomy and systemic risk, see Giglio et al. (2016).

Lastly, our work is related to a very large literature that uses network analysis to address issues related to systemic risk in banking systems. The interested reader is referred to the literature reviews on this subject by Acemoglu et al. (2017b), Babus and Allen (2009), Bougheas and Kirman (2015), and Glasserman and Young (2016).

\section{The Model Without Fire Sales}

Time is discrete $(t=0,1, \ldots)$; each period $t$ is divided into sub-periods $(\tau=$ $0,1, \ldots)$. There is a set of $n$ banks with a typical element $b_{i}$, where $(i=1, \ldots, n)$. Table 1 shows the general form of a bank balance sheet:

Table 1. Bank balance sheet

\begin{tabular}{l|l}
\hline Assets & Liabilities \\
\hline Reserves: $R_{i}$ & Deposits from Households: $D_{i}^{H}$ \\
\hline Loans to Households: $L_{i}^{H}$ & Deposits from other Banks: $D_{i}^{B}$ \\
\hline Loans to Banks: $L_{i}^{B}$ & Equity: $E_{i}$ \\
\hline
\end{tabular}

There is a single divisible good that banks can (a) hold as reserves, (b) lend it to households to finance projects, and (c) lend it to other banks. Banks accept

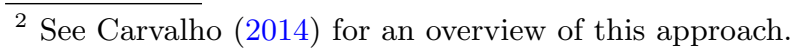


deposits form households and from other banks (loans from other banks). We assume bank equity is given by:

$$
E_{i} \equiv R_{i}+L_{i}^{H}+L_{i}^{B}-D_{i}^{H}-D_{1}^{B}
$$

Further, the following condition must hold for any closed bank network:

$$
\sum_{i=1}^{n} L_{i}^{B}=\sum_{i=1}^{n} D_{i}^{B}
$$

We set the net interest rate on household deposits $r_{D}$ equal to 1 , the net interest rate on household loans $r_{L}$ equal to $\frac{1}{\theta}$ (given (a) limited liability debt contracts, and (b) zero-profit condition for risk-neutral banks), and the net interest rate on interbank loans $r_{B}$ equal to $\frac{1+\theta}{2 \theta}$ (nash-bargaining splits the difference between the interest rates on households loans and household deposits between the two banks). ${ }^{3}$

At the beginning of each period $t(\tau=0)$ the balance sheet of $b_{i}$ is shown on Table 2 (all entries are endogenously determined):

Table 2. Bank balance sheet at $(\tau=0)$

\begin{tabular}{l|l}
\hline Assets & Liabilities \\
\hline$R_{i 0} \geqslant 0$ & $D_{i 0}^{H} \geqslant 0$ \\
\hline$L_{i 0}^{H}=0$ & $D_{i 0}^{B}=0$ \\
\hline$L_{i 0}^{B}=0$ & $E_{i 0} \geqslant 0$ \\
\hline
\end{tabular}

Projects. Projects require 1 unit of investment, last for one period and yield a stochastic return. With probability $\theta$ they yield a gross return $Z$ and with probability $1-\theta$ they fail yielding nothing, where $\theta Z \geqslant 1$. Projects returns are independently distributed.

Network Formation. The demand for project financing is infinitely elastic. Projects are financed sequentially and the allocation of projects to banks is random. As long as there exists at least one bank with reserves greater of equal to unity the banking system will keep financing new projects. Thus, the aggregate credit provided each period will be approximately equal to aggregate reserves. ${ }^{4}$ Suppose that $b_{i}$ is allocated a project. If $R_{i} \geqslant 1, b_{i}$ offers a loan and the following two changes take place on its balance sheet $\Delta L_{i}^{H}=+1$ and $\Delta R_{i}=-1$. If $R_{i}<1$ then $b_{i}$ randomly selects another bank, say $b_{j}$ and request an interbank loan.

\footnotetext{
${ }^{3}$ It will become clear below that our qualitative results are not sensitive to the processes by which the three interest rates are determined.

4 To keep the program simple we do not allow projects to be financed by multiple banks. This means that aggregate lending might be less that aggregate reserves. However, given that the number of banks is small relatively to the amount of aggregate reserves this simplification will not have any qualitative influence on our results.
} 
If $R_{j} \geqslant 1, b_{j}$ offers an interbank loan to $b_{i}$ and the latter finances the project. The balance sheet changes for the two banks are given by: $\Delta D_{i}^{B}=+1, \Delta L_{i}^{H}=+1$, $\Delta R_{j}=-1$ and $\Delta L_{j}^{B}=+1$. If $R_{j}<1$ then $b_{i}$ repeats the process by randomly selecting one of the remaining banks. The whole process terminates when no bank has reserves greater or equal to unity. At the end of the network formation process $(\tau=1)$ the balance sheet of $b_{i}$ is shown on Table 3 :

Table 3. Bank balance sheet at $(\tau=1)$

\begin{tabular}{l|l}
\hline Assets & Liabilities \\
\hline$R_{i 1}<1$ & $D_{i 1}^{H} \geqslant 0$ \\
\hline$L_{i 1}^{H} \geqslant 0$ & $D_{i 1}^{B} \geqslant 0$ \\
\hline$L_{i 1}^{B} \geqslant 0$ & $E_{i 1} \geqslant 0$ \\
\hline
\end{tabular}

Household Loan Repayments. Close to the end of period $t$ project returns are realized and loans granted for successful projects are repaid. Despite the fact that project returns are independently distributed the finiteness of a bank's loan portfolio implies that bank equity can take negative values, that is banks can become insolvent. Now, balance sheets also reflect the interest payments due. Table 4 shows the bank balance sheet after loans are repaid or written off but before the interbank market clears $(\tau=2)$ :

Table 4. Bank balance sheet at $(\tau=2)$

\begin{tabular}{l|l}
\hline Assets & Liabilities \\
\hline$R_{i 2} \geqslant 0$ & $D_{i 2}^{H}=D_{i 1}^{H}$ \\
\hline$L_{i 2}^{H}=0$ & $D_{i 2}^{B}=\frac{1+\theta}{2 \theta} D_{i 1}^{B}$ \\
\hline$L_{i 2}^{B}=\frac{1+\theta}{2 \theta} L_{i 1}^{B}$ & $E_{i 0} \gtrless 0$ \\
\hline
\end{tabular}

Reserves have been augmented by loan repayments. As projects last only one period all loans to households are either repaid or written off. Identity (1) is used for the calculation of bank equity.

Bankruptcy Resolution Process (No Fire Sales). All banks with negative equity are insolvent and they will be liquidated. The proceeds of the liquidation process will be distributed pro rata to all the liability holders. In this section, we assume that the market value of liquidated assets are equal to their book values. That is, for the moment, we assume no fire sales. Below we extend our model by including fire sales. We follow the method proposed by Eisenberg and Noe (2001) for clearing the banking network. This procedure, at least for the case with 
no fire sales, is independent of the order that insolvent banks are liquidated. ${ }^{5}$ This is because interbank loans are only settled after the bankruptcy resolution process is completed. Completion implies either that all remaining banks are solvent or that no banks are left. Below we describe the algorithm that we used to implement the procedure.

If there are any banks with negative equity choose one randomly, say $b_{i}$. Let $\lambda \equiv \frac{D_{i 2}^{H}}{D_{i 2}^{H}+D_{i 2}^{B}}$; the ratio of household deposits to total deposits. Let $d_{i}^{j}$ denote the liabilities of $b_{i}$ to $b_{j}$ (interbank loan from $b_{j}$ to $b_{i}$ ). Let $l_{i}^{k} \equiv d_{k}^{i}$ denote an interbank loan from $b_{i}$ to $b_{k} .{ }^{6}$ Then, the assets of $b_{i}$ will be distributed to its creditors pro rata as follows ${ }^{7}$ : The depositors of $b_{i}$ will receive a fraction $\lambda$ of (a) $R_{i 2}$, and (b) $l_{i}^{k}$ for all $k(1, \ldots, n) .{ }^{8}$ Each bank $b_{j}$ such that $d_{i}^{j}>0$ will receive a fraction $\frac{d_{i}^{j}}{D_{i 2}^{H}+D_{i 2}^{B}}$ of (a) (a) $R_{i 2}$, and (b) $l_{i}^{k}$ for all $k(1, \ldots, n)$. Given that $\sum_{j=1}^{n} d_{i}^{j}=D_{i 2}^{B}$ the above process will redistribute all the assets of $b_{i}$ to its two classes of creditholders.

Next consider changes on the balance sheets of all other banks following the resolution of $b_{i}$. Consider any bank $b_{j}$ such that $d_{i}^{j}>0$ and any bank $b_{k}$ such that $d_{k}^{i}>0$. Then,

1. $b_{k}$ will set its liabilities to $b_{i}$ equal to zero: $\Delta d_{k}^{i}=-d_{k}^{i}$;

2. $b_{k}$ will increase its household deposits: $\Delta D_{k 2}^{H}=\lambda d_{k}^{i}$;

3. $b_{k}$ will increase its deposits by bank $b_{j}: \Delta d_{k}^{j}=\frac{d_{i}^{j}}{D_{i 2}^{H}+D_{i 2}^{B}} d_{k}^{i}$;

4. $b_{j}$ will set its loan to $b_{i}$ equal to zero: $\Delta l_{j}^{i}=-l_{j}^{i}$;

5. $b_{j}$ will increase its loans to bank $b_{k}: \Delta l_{j}^{k}=\frac{d_{i}^{j}}{D_{i 2}^{H}+D_{i 2}^{B}} d_{k}^{i}$.

This will end the bankruptcy procedure for $b_{i}$. Notice that given that some of the creditors of $b_{i}$ were not fully repaid it is possible that some banks that before the above process were solvent now they are insolvent. If there are any banks insolvent then by choosing one of them randomly the whole procedure repeats itself. If there are no more insolvent banks the bankruptcy resolution process terminates. After the resolution process all the assets of insolvent banks would have been distributed between their depositors and the remaining banks.

\footnotetext{
${ }^{5}$ Uniqueness is achieved under very mild conditions. In the Appendix we provide a numerical example.

${ }^{6}$ According to the network formation process of our model it is possible that both $L_{i 2}^{H}$ and $D_{i 2}^{H}$ to be positive. However, you cannot have a pair of banks where each one has offered a loan to the other.

${ }^{7}$ In this work we have followed Eisenberg and Noe (2001) and have assumed that all creditors are treated equal. As Acemoglu et al. (2015) have shown the clearing process can easily be modified to allow a class of creditholders (e.g. depositors) to have a priority claim over the bank's assets. There is an ongoing debate over the design of optimal priority rules for banks (for a review of the relevant literature see Bougheas and Kirman 2016).

${ }^{8}$ Clearly $l_{i}^{i}=0$, and $l_{i}^{k}=0$ if $b_{i}$ has not offered a loan to $b_{k}$.
} 
Interbank Market Clearing. Given that all remaining banks are solvent all outstanding loans in the interbank market can be settled. After the interbank market is cleared the balance sheets of solvent banks will have exactly the same form as those at $\tau-0$.

Dynamics. In order to complete the description of the model we need to specify how the initial balance sheets are formed, what happens to the banking systems after some banks failed and what happens to the depositors of failed banks.

At $t=0$, each bank is randomly allocated reserves, $R$, drawn form a uniform distribution with support $[0, \bar{R}]$. Household deposits are set equal to a fixed ratio $\delta$ of reserves. Thus, bank equity is equal to $(1-\delta) R$.

At the end of each period $t$, new banks enter to replace the ones that have been insolvent. We make this assumption to ensure that the banking system does not vanish. It would then seem natural to have households whose original banks became insolvent to deposit their funds at the new banks. However, there is a problem. On one hand, new banks, on average, would be smaller in size as their depositors have suffered losses. On the other hand, given that the allocation of projects to banks is random these new banks would by disproportionately highly indebted to other banks and given that their equity levels would also be low they would fail again with a high probability. Put differently, the dynamics of the system would be such that in the long-run the banking system would artificially become very highly concentrated. There are two possible ways to avoid this problem. The fist one, and the one that we have followed in this paper, is to have all reserves randomly redistributed in the system. While this approach is much simpler and, as a result, our main results very easy to interpret, it destroys some interesting dynamic interactions. The second approach is to allow households who had deposits at failed institution to have them now depositing their funds at the new banks but now change the network formation process so that banks with higher reserves have a higher probability of being allocated a project. This second approach is more realistic, however, when we introduce fire sales, it makes it more difficult to assess the exact mechanism that produces the distribution of aggregate credit shocks.

Lastly, we adjust equity and deposits at each bank so that at the beginning of $t+1$ the ratio of deposits to reserves is equal to $\delta .^{9}$

\section{Results Without Fire Sales}

The number of banks that will become insolvent each period would depend on three factors. The first factor is the realized proportion of successful projects. Even if each project fails with probability $1-\theta$, the economy is finite and the law of large numbers does not hold. The resulting aggregate uncertainty implies that the realized proportion of successful projects will vary over time.

\footnotetext{
${ }^{9}$ The recapitalization is clearly necessary for all new banks that otherwise would begin with no equity.
} 
The second factor is the distribution of failed projects across the banking system. Other things equal, the more uneven this distribution is the higher the numbers of insolent banks will be. The third factor is the structure of the banking network. Acemoglu et al. (2015) have shown that as long as the initial losses are not to large a more connected banking system can provide a buffer against contagion as losses are distributed across many banks. In contrast, when initial losses are large a less connected system might prevent such contagion.

Even if it is difficult to predict the number of banks that will fail following an aggregate shock, the level aggregate of credit provided by the banking system follows a well defined pattern. At the beginning of each period $t$ aggregate credit is approximately equal to aggregate reserves, $\hat{R}_{t} \cdot{ }^{10}$ Projects that are successful boost reserves and equity of the banks that financed them. The losses of the projects that failed are initially absorbed by the equity of the banks that financed them. If this equity is not large enough to absorb the losses then the creditholders of the bank absorb the losses, that is its depositors and other banks.
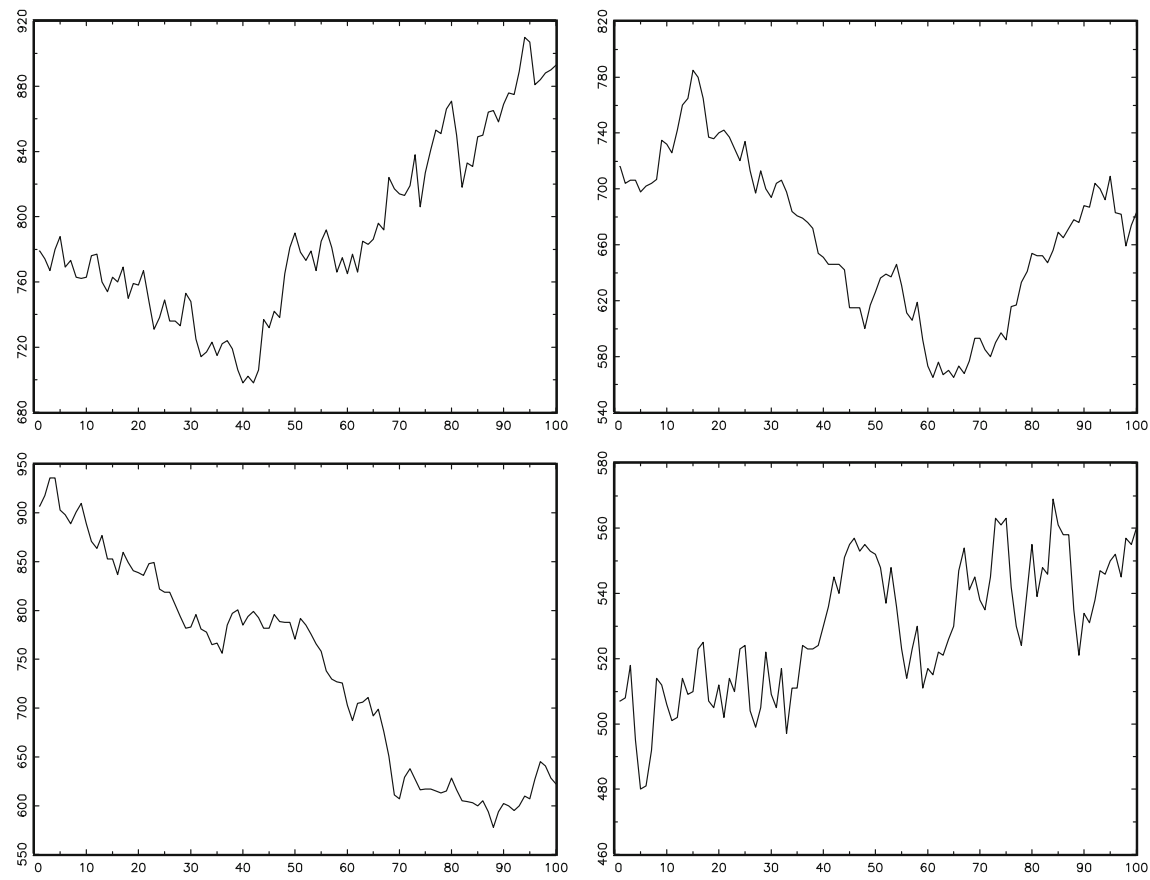

Fig. 1. Aggregate credit, no fire sales

\footnotetext{
10 The approximation qualification is due to the fact that we do allow banks to cofinance projects and thus aggregate credit is less than or equal to aggreagte reserves but more than or equal to aggregate reserves minus the number of banks. Given that the number of banks is relative to the level of aggregate reserves is relatively small in what follows we ignore this approximation.
} 
Thus when the process ends all losses have been absorbed either by the depositors or equityholders. Given that at the end of the period all liquidation proceeds are redeposited in the banking system aggregate credit follows a random walk (with drift if $\theta Z>1$ ).

$$
\hat{R}_{t+1}=\hat{R}_{t}+\varepsilon_{t}
$$

Notice that the error term depends on the realized number of successful projects and thus it is binomially distributed, however, the fact that the number of projects is large implies that the distribution is approximately normal.

The introduction of fire sales below complicates significantly the dynamic behavior of the model and we will have to use calibrations. Below we present calibration results for the benchmark case when fire sales are set equal to zero.

Numerical Results. For our calibration exercise we set the following parameter values: $n=20, \bar{R}=100, \theta=0.8, Z=1.25$, and $\delta=0.8$. In this particular case there is no growth as $\theta Z=1$. The four panels of Fig. 1 show four of aggregate credit for 100 periods, while the four panels of Fig. 2 show the corresponding runs of the first differences of aggregate credit activity. These examples just verify our assertion that without fire sales the dynamic path of aggregate credit not inconsistent with a random walk process.
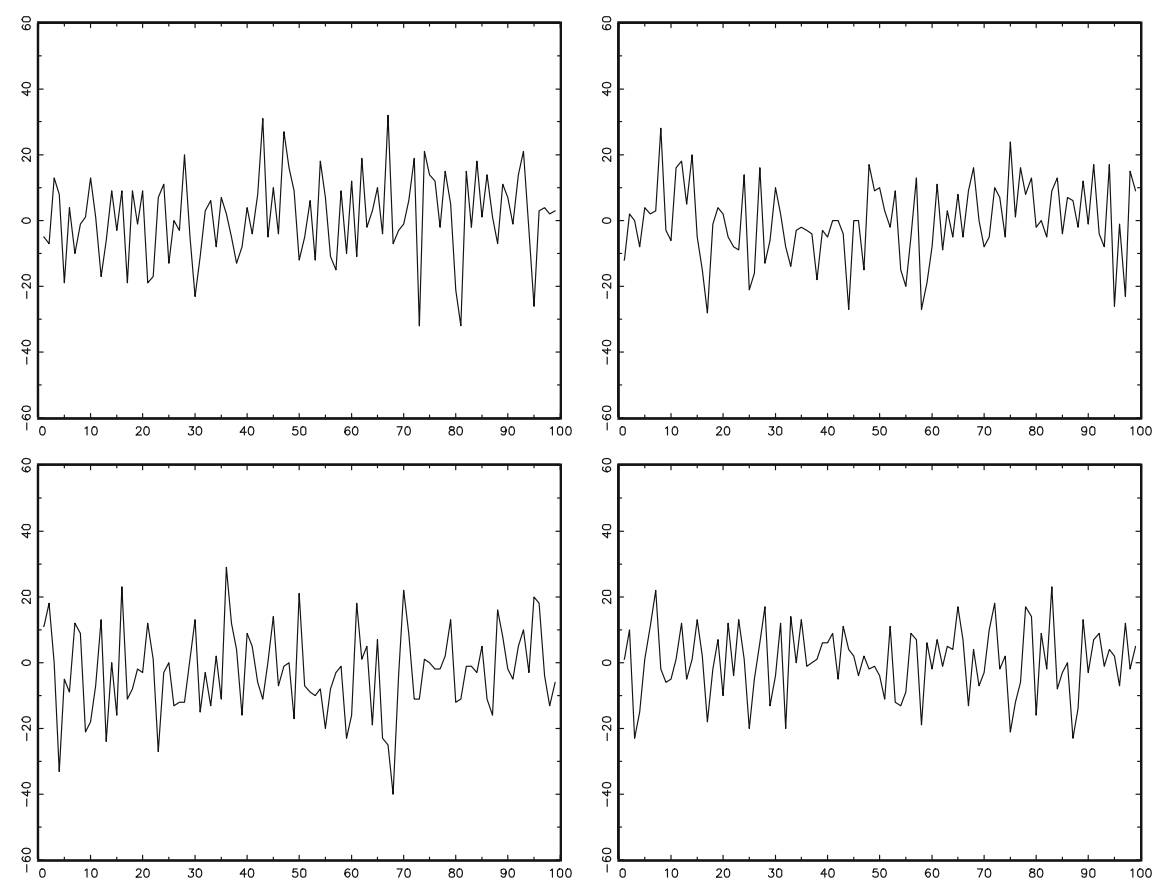

Fig. 2. First differences of aggregate credit, no fire sales 


\section{The Model with Fire Sales}

In our model the only assets that banks hold when they get liquidated are reserves and loans to other banks. In reality banks would hold many other assets including outstanding loans to households. When banks are forced to liquidate any assets, either loans to households (firms) or any other liquid assets that they hold as reserves, the prices of these assets can fall below their book values. Such a fall in prices can be the result of either (a) asymmetric information problems arising from allocating assets, such as loans to firms, to new creditors, or (b) price externalities generated when many institutions are attempting to sell their assets at the same time. The first to consider fire sales within a financial equilibrium framework was Shleifer and Vishny (1992). More closely relate to our work Caballero and Simsek (2013) have considered fire sales in a banking network. $^{11}$

As we have demonstrated in the section above, without introducing liquidation costs the aggregate performance of the banking system is completely determined by the realized distribution of initial shocks. Put differently, the network structure only affects the distribution of gains and losses across the system but not their aggregate value.

When we analyzed above the bankruptcy resolution process for the case without liquidation costs we noted that insolvent banks distribute their reserves $R_{i 2}$ pro rata among their creditors. The presence of liquidation costs implies that now the value of reserves (liquid assets) distributed $R_{i 3}$ will be lower than $R_{i 2}$.

Below we consider two alternative amplification mechanisms for aggregate shocks.

Linear Liquidation Costs. Suppose that when a bank's assets (reserves) are liquidated they lose a fraction $f$ of their book value. Thus, we have

$$
R_{i 3}=(1-f) R_{i 2}
$$

The linearity restriction refers to the fact that $f$ is independent of the number of banks that become insolvent, $\hat{n} \leqslant n$. The availability of aggregate credit at the beginning of the next period will depend on how the following three factors affect $\hat{n}$ : (a) the aggregate value of loan repayments (b) the distribution of loan repayments across the network, and (c) the structure (topology), $g$, of the network.

Without liquidation costs the evolution of aggregate credit depended only on the aggregate value of loan repayments. However, with the introduction of liquidity costs the performance of aggregate credit will now depend on the other

${ }^{11}$ For assets that are not liquid traditional 'mark to market' accounting evaluation methods tend to exacerbate such problems. This is because such asset reevaluations might also affect institutions that are not directly connected with institutions that have become insolvent. In our work we are unable to capture such effects given that we do not explicitly allow for illiquid assets. 
two factors. ${ }^{12}$ For a given network structure, the total losses would depend on how connected the affected banks are. For example, isolated banks do not impose any external effects. But the total losses would also depend on the structure of the network itself (see Acemoglu et al. 2015).

Thus, whether or not the linear case is sufficient to produce fat tails in the distribution of aggregate credit would depend on how the last two factors affect $\hat{n}$.

Non-Linear Liquidation Costs. In this case we allow for the liquidation cost to depend on the number of banks that become insolvent. Suppose that $b_{i}$ is the $j$ th bank that is liquidated. Then, we let

$$
R_{i 3}=(1-f)^{j} R_{i 2}
$$

The idea here is that as the number of banks that become insolvent increase the more depressed asset values become.
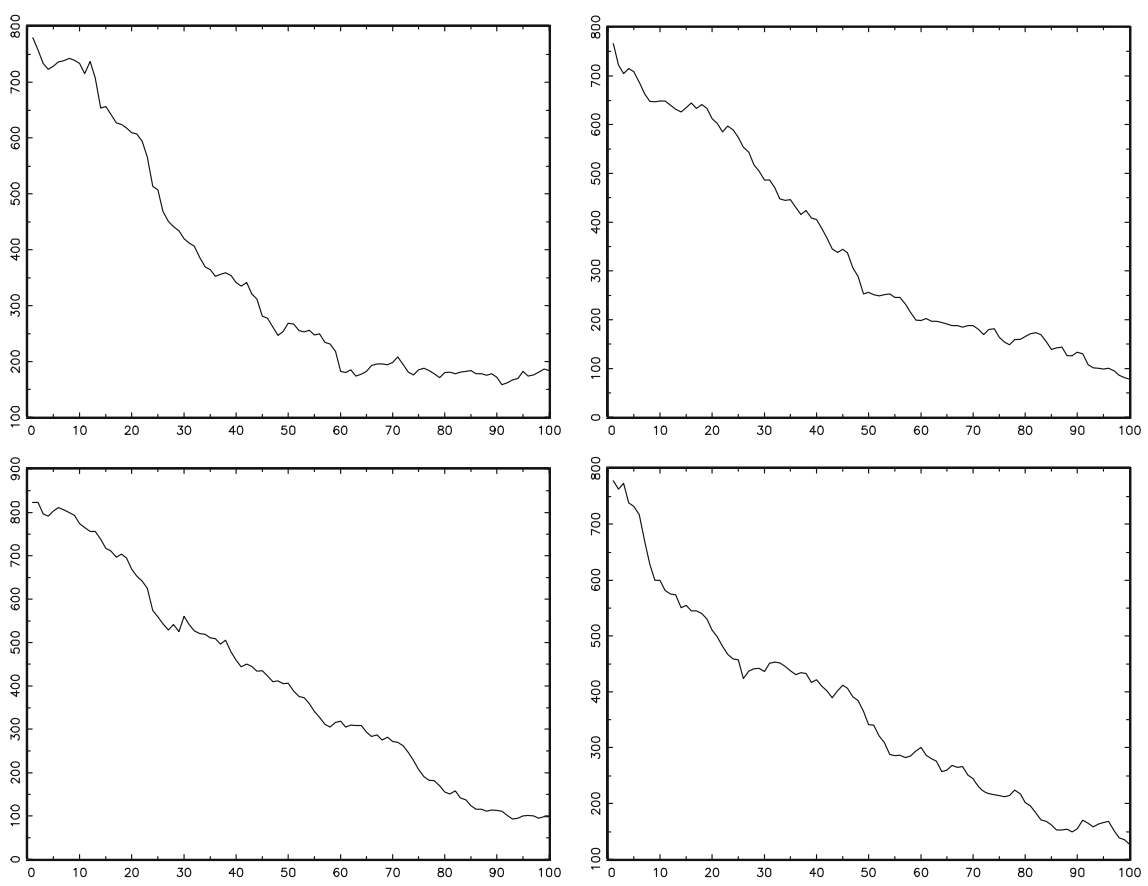

Fig. 3. Aggregate credit, fire sales

$\overline{12}$ The amplification mechanism is asymmetric as it affects only losses. However as we will see below, even if the initial aggregate shoch is positive, that is the number of successful $\mathrm{p}$ [ojects is greater than $\theta$, depending on the distribution of failed projects across the banking system it is still possible that aggregate credit declines. 


\section{$5 \quad$ Results with Fire Sales}

We use the same parameters as for the case without fire sales and we also set $f=0.05$.

There is one additional complication when we introduce fire sales. We have noted above that for the case without liquidation costs the final outcome of the bankruptcy resolution process does not depend on the exact sequence by which insolvent banks are liquidated. Unfortunately, this is not the case anymore. We control for this complication by allowing for multiple randomizations after we reach that stage.

The four panels of Fig. 3 show four of aggregate credit while the four panels of Fig. 4 show the corresponding runs of the first differences of aggregate credit activity. Comparing these figures with the corresponding figures obtained in the case without fire sales we make the following observations. From Fig. 3 we find that aggregate credit almost vanishes. This is because the asymmetry of the amplification mechanism. While there is nothing to boost the performance of institutions that are unaffected by bankruptcies those that are affected are suffering from additional losses due to fire sales. Without compensating by allowing for growth, that is $\theta Z>1$, the distribution is not stationary. Nevertheless, Fig. 4, at least in the early periods when the size of the banking system is still relatively large, clearly shows that the magnitude of negative shocks has increased.
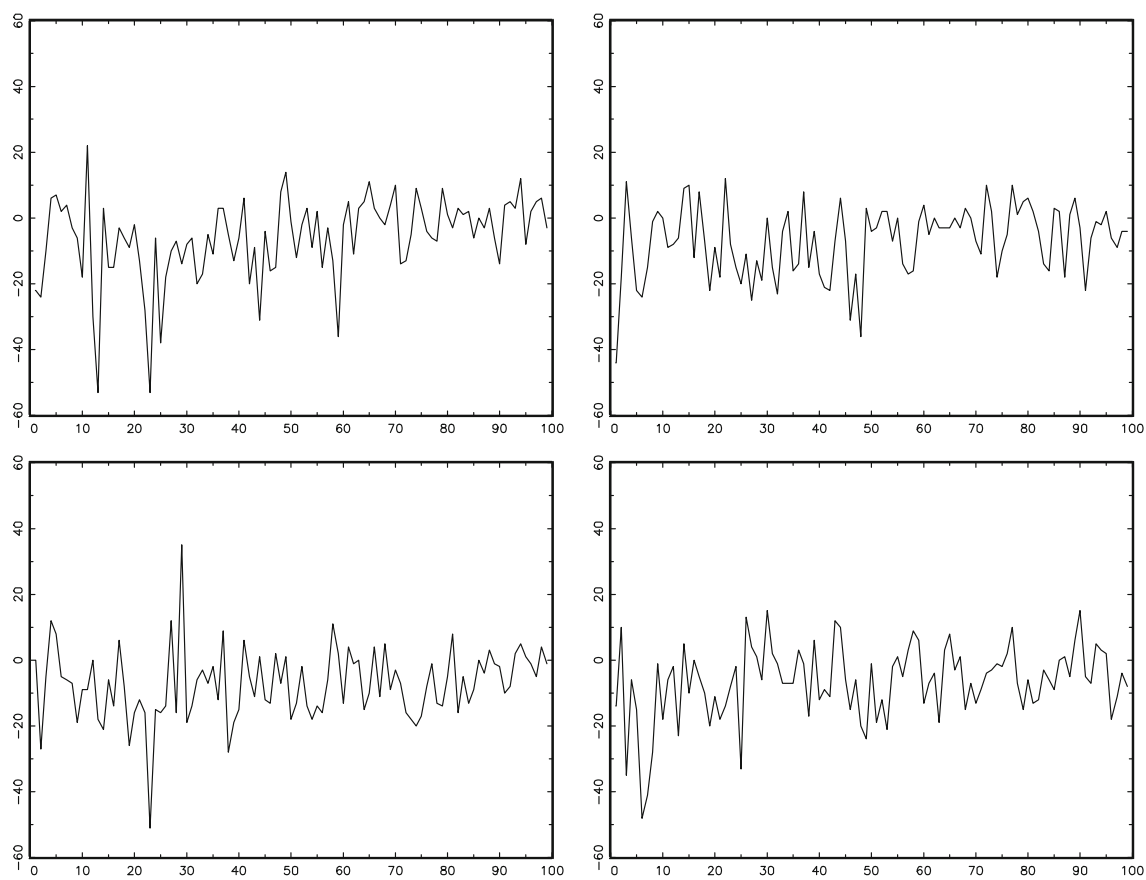

Fig. 4. First differences of aggregate credit, fire sales 
These preliminary observations provide hints that our proposed mechanism might account for both the fat tails and the asymmetric nature of the distribution of aggregate economic activity over time.

\section{Conclusion}

We have suggested that some of the properties of the time series of aggregate output might be accounted by the behavior of aggregate credit activity. Our work provides a microfoundations explanation for the relationship between the provision of aggregate credit and macroeconomic crises observed by Schularick and Taylor (2012). In particular, we have argued that by analyzing the causes of systemic risk in the financial system can potentially help us understand both the presence of fat macroeconomic tail risk and the asymmetry between booms and busts along the business cycle.

We have captured systemic risk through an interbank network with links representing interbank exposures. Each period banks borrow and lend to each other so that they can finance loans to households that are randomly allocated across the banking system. Given that households loans are risky and lack of complete diversification the loan portfolio of each bank is also risky and banks can become insolvent. By applying standard methods for the bankruptcy resolution process we have captured the process of contagion across the banking system as failing banks put at risk their own creditors and thus providing a measure of systemic risk.

We have presented some preliminary numerical results where we compare two versions of our model, namely, one with and one without fire sales, for the case when there is no economic growth. For the case without fire sales we have shown that aggregate credit follows a random walk. The introduction of fire sales has significantly amplified negative shocks on aggregate credit. Without a stabilizing mechanism at the limit aggregate credit vanishes. Below we discuss our plans for extending the present work.

Our first priority is to allow for growth by setting $\theta Z>1$ so that the distribution of the growth rate of aggregate credit becomes stationary. We will be able then to compare the moments of the distribution for the two versions of our model and thus provide a quantitative assessment of the ability of our model to produce both fat tails and asymmetries in the distribution of aggregate credit.

As we explained in Sect. 2, unless we introduce a mechanism for rebalancing the system we would end up with some small-size banks being heavily indebted and thus repeatedly failing. In order to avoid this from happening we have, at the end of each period, redistributed deposits across the banking system. Doing so has allowed us to keep the network formation process completely random. We plan to explore an alternative method where larger banks face a higher demand for household loans. This is a more natural way to model the banking system, however, the disadvantage is that we introduce another potential source of variation in the model, mainly tails in the distribution of the size of banks, that could also affect systemic risk. However, comparing the two methods we should be able to disentangle these effects. 
Another important task would be to try to improve our understanding of the relationship between network structure and systemic risk. We can do that by producing estimates for network measures (e.g. average degree, centrality) for each period of our model and then by checking how these measures are correlated with the corresponding growth rates of aggregate credit at the end of the period and the aggregate shock at the beginning of the period.

Lastly, our plan is to embed the whole banking structure in an agent-based model of the whole economy so that we can assess how fluctuations in the supply of credit are related to booms and busts of the economy. At the minimum, we would hope that our model would account for the fat tails in the growth rate of aggregate economic activity and the asymmetry in the patterns between booms and busts. However, by also allowing for an endogenous growth process we would hope that the more general framework would also provide an account not only for the long-term growth patterns of economic activity but also for the persistence in aggregate shocks.

Acknowledgement. We would like to acknowledge financial support from COST Action IS1104 "The EU in the new economic complex geography: models, tools and policy analysis".

\section{A Appendix: Numerical Example}

We present an example that demonstrates how the bankruptcy resolution process works and why the outcome is independent of the order of bank resolutions. There are three banks: $b_{1}, b_{2}$ and $b_{3}$. For ease of exposition we have set all net interest rates equal to 0 . The balance sheets of the three banks at the beginning of the period are given by (Table 5):

Table 5. A1: Initial balance sheets

\begin{tabular}{l|l|l|l}
\hline & $b_{1}$ & $b_{2}$ & $b_{3}$ \\
\hline$R$ & 1 & 1 & 1 \\
\hline$L^{H}$ & 0 & 2 & 2 \\
\hline$L^{B}$ & $1\left(b_{2}\right)$ & $1\left(b_{3}\right)$ & 0 \\
\hline Assets & 2 & 4 & 3 \\
\hline$D^{H}$ & 1 & 2 & 1 \\
\hline$D^{B}$ & 0 & $1\left(b_{1}\right)$ & $1\left(b_{2}\right)$ \\
\hline$E$ & 1 & 1 & 1 \\
\hline Liabilities & 2 & 4 & 3 \\
\hline
\end{tabular}

Suppose that all projects failed. Then the three balance sheets after the writing off of losses are given by (Table 6): 
Table 6. A2: Balance sheets adjusted for losses

\begin{tabular}{l|l|l|l}
\hline & $b_{1}$ & $b_{2}$ & $b_{3}$ \\
\hline$R$ & 1 & 1 & 1 \\
\hline$L^{H}$ & 0 & 0 & 0 \\
\hline$L^{B}$ & $1\left(b_{2}\right)$ & $1\left(b_{3}\right)$ & 0 \\
\hline Assets & 2 & 2 & 1 \\
\hline$D^{H}$ & 1 & 2 & 1 \\
\hline$D^{B}$ & 0 & $1\left(b_{1}\right)$ & $1\left(b_{2}\right)$ \\
\hline$E$ & 1 & -1 & -1 \\
\hline Liabilities & 2 & 2 & 1 \\
\hline
\end{tabular}

Banks $b_{2}$ and $b_{3}$ are insolvent. ${ }^{13}$ We need to consider two cases:

Bankruptcy Resolution Process Begins with $b_{3}$. The reserves of $b_{3}$ will be divided equally between the depositors of $b_{3}$ and $b_{2}$. After this step the balance sheets are given by (Table 7$)$ :

Table 7. A3: Balance sheets after the resolution of $b_{3}$

\begin{tabular}{l|l|l|l}
\hline & $b_{1}$ & $b_{2}$ & $b_{3}$ \\
\hline$R$ & 1 & 1.5 & 0.5 \\
\hline$L^{H}$ & 0 & 0 & 0 \\
\hline$L^{B}$ & $1\left(b_{2}\right)$ & 0 & 0 \\
\hline Assets & 2 & 1.5 & 0.5 \\
\hline$D^{H}$ & 1 & 2 & 0.5 \\
\hline$D^{B}$ & 0 & $1\left(b_{1}\right)$ & 0 \\
\hline$E$ & 1 & -1.5 & 0 \\
\hline Liabilities & 2 & 3 & 0.5 \\
\hline
\end{tabular}

The reserves of $b_{2}$ will be divided pro-rata between the depositors of $b_{2}$ and $b_{1}$. After this step the balance sheets are given by (Table 8):

${ }_{13}$ After a bank is liquidated it cheases to exist. However, to keep track of what happened to its depositors we assume that another bank (with the same name) has replaced it where households can deposit their liquidation proceeds. 
Table 8. A4: Balance sheets after the resolution of $b_{2}$

\begin{tabular}{l|l|l|l}
\hline & $b_{1}$ & $b_{2}$ & $b_{3}$ \\
\hline$R$ & 1.5 & 1 & 0.5 \\
\hline$L^{H}$ & 0 & 0 & 0 \\
\hline$L^{B}$ & 0 & 0 & 0 \\
\hline Assets & 1.5 & 1 & 0.5 \\
\hline$D^{H}$ & 1 & 1 & 0.5 \\
\hline$D^{B}$ & 0 & 0 & 0 \\
\hline$E$ & 0.5 & 0 & 0 \\
\hline Liabilities & 1.5 & 1 & 0.5 \\
\hline
\end{tabular}

The process has been completed.

Bankruptcy Resolution Process Begins with $b_{2}$. The reserves and deposits in $b_{3}$ of $b_{2}$ will be divided pro-rata between the depositors of $b_{2}$ and $b_{1}$. The depositors of $b_{2}$ will receive $2 / 3$ in reserves (keep them as deposits) and $2 / 3$ in deposits in $b_{3} . b_{1}$ will receive $1 / 3$ in reserves and $1 / 3$ in deposits in $b_{3}$. After this step the balance sheets are given by (Table 9$)$ :

Table 9. A5: Balance sheets after the resolution of $b_{2}$

\begin{tabular}{l|l|l|l}
\hline & $b_{1}$ & $b_{2}$ & $b_{3}$ \\
\hline$R$ & $4 / 3$ & $2 / 3$ & 1 \\
\hline$L^{H}$ & 0 & 0 & 0 \\
\hline$L^{B}$ & $1 / 3\left(b_{3}\right)$ & 0 & 0 \\
\hline Assets & $5 / 3$ & $2 / 3$ & 1 \\
\hline$D^{H}$ & 1 & $2 / 3$ & $5 / 3$ \\
\hline$D^{B}$ & 0 & 0 & $1 / 3\left(b_{1}\right)$ \\
\hline$E$ & $2 / 3$ & 0 & -1 \\
\hline Liabilities & $5 / 3$ & $2 / 3$ & 1 \\
\hline
\end{tabular}

The reserves of $b_{3}$ will be divided pro rata between the depositors of $b_{2}$ depositors of $b_{3}$ and $b_{1}$. Depositors of $b_{3}$ will receive $1 / 2$ in reserves, depositors of $b_{2}$ will receive $1 / 3$ in reserves and $b_{1}$ will receive $1 / 6$ in reserves. After this step the balance sheets are given by (Table 10): 
Table 10. A6: Balance sheets after the resolution of $b_{3}$

\begin{tabular}{l|l|l|l}
\hline & $b_{1}$ & $b_{2}$ & $b_{3}$ \\
\hline$R$ & 1.5 & 1 & 0.5 \\
\hline$L^{H}$ & 0 & 0 & 0 \\
\hline$L^{B}$ & 0 & 0 & 0 \\
\hline Assets & 1.5 & 1 & 0.5 \\
\hline$D^{H}$ & 1 & 1 & 0.5 \\
\hline$D^{B}$ & 0 & 0 & 0 \\
\hline$E$ & 0.5 & 0 & 0 \\
\hline Liabilities & 1.5 & 1 & 0.5 \\
\hline
\end{tabular}

The process has been completed. The results for the two cases are identical.

\section{References}

Acemoglu, D., Carvalho, V., Ozdaglar, A., Tahbaz-Salehi, A.: The network origins of aggregate fluctuations. Econometrica 80, 1977-2016 (2012)

Acemoglu, D., Ozdaglar, A., Tahbaz-Salehi, A.: Systemic risk and stability in financial networks. Am. Econ. Rev. 105, 564-608 (2015)

Acemoglu, D., Ozdaglar, A., Tahbaz-Salehi, A.: Microeconomic origins of macroeconomic tail risks. Am. Econ. Rev. 107, 54-108 (2017a)

Acemoglu, D., Ozdaglar, A., Tahbaz-Salehi, A.: Networks, shocks, and systemic risk. In: Bramoulle, Y., Galeotti, A., Rogers, B. (eds.) The Oxford Handbook on the Economics of Networks. Oxford University Press, NY (2017b)

Acemoglu, D., Scott, A.: Asymmetric business cycles: theory and time-series evidence. J. Monetary Econ. 40, 501-533 (1991)

Anthonissen, N.: Microeconomic shocks and macroeconomic fluctuations in a dynamic network economy. J. Macroecon. 47, 233-254 (2016)

Ascari, G., Fagiolo, G., Roventini, A.: Fat-tail distributions and business cycle models. Macroecon. Dyn. 19, 415-476 (2015)

Ashraf, Q., Gershman, B., Howitt, P.: Banks, market organization, and macroeconomic performance: an agent-based computational analysis. J. Econ. Behav. Organ. 135, 143-180 (2017)

Babus, A., Allen, F.: Networks in finance. In: Kleindorfer, P., Wind, J. (eds.) NetworkBased Strategies and Competencies, pp. 367-382. Wharton School Publishing, Upper Saddle River (2009)

Battiston, S., Delli Gatti, D., Gallegati, M., Greenwald, B., Stiglitz, J.: Credit chains and bankruptcy propagation in production networks. J. Econ. Dyn. Control 31, 2061-2084 (2007)

Bougheas, S., Kirman, A.: Complex financial networks and systemic risk: a review. In: Commendatore, P., Kayam, S., Kubin, I. (eds.) Complexity and Geographical Economics: Topics and Tools. Springer, Heidelberg (2015)

Bougheas, S., Kirman, A.: Bank insolvencies, priority claims and systemic risk. In: Commendatore, P., Matilla-Garcia, M., Varela, L., Canovas, J. (eds.) Complex Networks and Dynamics: Social Economic Interactions. Springer, Heidelberg (2016) 
Caballero, R., Simsek, A.: Fire sales in a model of complexity. J. Finance 68, 2549-2587 (2013)

Carvalho, V.: From micro to macro via production networks. J. Econ. Perspect. 28, 23-248 (2014)

Diamond, D., Rajan, R.: Fear of fire sales, illiquidity seeking, and credit freezes. Q. J. Econ. 126, 557-591 (2011)

Eisenberg, L., Noe, T.: Systemic risk in financial systems. Manag. Sci. 47, 236-249 (2001)

Geanakoplos, J., Axtell, R., Farmer, D., Howitt, P., Conlee, B., Goldstein, J., Hendrey, M., Palmer, N., Yang, C.-Y.: Getting at systemic risk via an agent-based model of the housing market. Am. Econ. Rev. Papers Proc. 102, 53-58 (2012)

Giglio, S., Kelly, B., Pruitt, S.: Systemic risk and the macroeconomy: an empirical evaluation. J. Financ. Econ. 119, 457-471 (2016)

Glasserman, P., Young, P.: Contagion in financial networks. J. Econ. Lit. 54, 779-831 (2016)

Schularick, M., Taylor, A.: Credit booms gone bust: monetary policy, leverage cycles, and financial crises 1870-2008. Am. Econ. Rev. 102, 1029-1061 (2012)

Shleifer, A., Vishny, R.: Liquidation values and debt capacity: a market equilibrium approach. J. Finance 47, 1343-1366 (1992)

Shleifer, A., Vishny, R.: Fire sales in finance and macroeconomics. J. Econ. Perspect. 25, 29-48 (2011)

Thurner, S., Farmer, D., Geanakoplos, J.: Leverage causes fat tails and clustered volatility. Quant. Finance 12, 695-707 (2012)

Open Access This chapter is licensed under the terms of the Creative Commons Attribution 4.0 International License (http://creativecommons.org/licenses/by/4.0/), which permits use, sharing, adaptation, distribution and reproduction in any medium or format, as long as you give appropriate credit to the original author(s) and the source, provide a link to the Creative Commons license and indicate if changes were made.

The images or other third party material in this chapter are included in the chapter's Creative Commons license, unless indicated otherwise in a credit line to the material. If material is not included in the chapter's Creative Commons license and your intended use is not permitted by statutory regulation or exceeds the permitted use, you will need to obtain permission directly from the copyright holder. 